\title{
A Presentist Approach to (Ersatz) Possible Worlds
}

\author{
Takeshi Sakon
}

\begin{tabular}{|c|l|}
\hline Citation & Acta Analytica, 31(2): 169-177 \\
\hline Issue Date & $2016-06$ \\
\hline Type & Journal Article \\
\hline Textversion & Author \\
\hline Rights & $\begin{array}{l}\text { This is a post-peer-review, pre-copyedit version of an article published in Acta Analytica. } \\
\text { The final authenticated version is available online at: } \\
\text { http://doi.org/10.1007/s12136-015-0271-y }\end{array}$ \\
\hline DOI & $10.1007 / \mathrm{s} 12136-015-0271-\mathrm{y}$ \\
\hline
\end{tabular}

\author{
Self-Archiving by Author(s) \\ Placed on: Osaka City University
}

Sakon, T. A Presentist Approach to (Ersatz) Possible Worlds. Acta Analytica. 31, 169-177 (2016). https://doi.org/10.1007/s12136-015-0271-y 


\section{A presentist approach to (ersatz) possible worlds}

\section{Time and modality}

It is sometimes argued that there is an analogy between time and modality: What is true of time, mutatis mutandis, should be true of modality, and vice versa. However, I think that the importance of this analogy has not been truly appreciated in the literature. In this paper, I try to offer a plausible account of the relationship between time and modality based on what is known as presentist ersatzism. While admitting that a time is not like a possible world, I will suggest that a time be taken as a certain sort of abstract object and that a possible world be identified with an ersatz B-series, a series of abstract times ordered by a primitive earlier than relation. One of the most important implications of this proposal is that ersatzists about time are better able to explain what possible worlds are. 


\section{Ersatzism about time}

First, let us see the modal dispute. Actualism is the thesis that everything is actual.

The rival view of (genuine) modal realism is the thesis that there are a vast number

of objects that may not exist in the actual world. Although both actualists and modal realists may agree that there are entities called 'possible worlds', they still disagree over the nature of those possible worlds. Modal realists think that possible worlds exist as concrete objects that are spatiotemporally and causally isolated from one another. In contrast, actualists typically think that they are not concrete objects but mere abstract representations of ways the world might have been.

What are we to think of these abstract representations of ways the world might have been? There are several options that actualists could adopt; however, let us focus on the most promising actualist approach known as linguistic ersatzism. Linguistic ersatzists define a possible world as a maximal consistent proposition or a maximal consistent set of propositions and then introduce an accessibility relation between possible worlds. Working within this framework, actualists may say that possible worlds exist not as concrete objects but as mere abstract objects. Therefore, 
actualists may use them for the analysis of modal statements.

Now, let us turn to the dispute between presentism and eternalism. Presentism is the thesis that everything is present. The rival view of eternalism is the thesis that there are a vast number of objects that may not exist at the present time. Although both presentists and eternalists may agree that there are entities called 'times', they still disagree over the nature of those times. Eternalists usually think that a time is something akin to a spatial point, whereas presentists resist such a view, stating instead that times are mere abstract representations of ways the present might have been.

What are we to think of those abstract representations of ways the present might have been? There are several options that presentists could adopt; however, let us focus on the theory known as ersatzist presentism (e.g. Bourne 2006 and Crisp 2007). Just as linguistic ersatzists define a possible world as a certain sort of abstract object, ersatzist presentists construct an ersatz time out of similar linguistic entities in the same manner. Ersatzist presentists then continue to say that abstract times form an ersatz B-series-a series of abstract times ordered by a 
primitive earlier than (or later than) relation. Working within this framework, presentists may say that a time is not anything like a place but a mere abstract object and use it for the analysis of tensed statements.

Ersatzism is useful for both actualists and presentists because it can provide a framework for the analysis of modality and tense without committing one to the existence of non-actual or non-present objects. Consider the modal case once again. It seems natural to say that $x$ exists at a place if and only if $x$ exists simpliciter. Similarly, modal realists typically hold that $x$ exists at a possible world if and only if $x$ exists simpliciter. As it is true to say that a talking donkey could exist, it exists at some possible world according to the familiar possible-worlds semantics. It then follows that a talking donkey exists simpliciter given the above truth-condition. Actualists, on the other hand, deny such a claim and will instead say that $x$ exists at a possible world $W$ if and only if $w$ implies or includes the proposition that $x$ exists. In this view, possible existence is just a matter of implication between propositions or set-theoretic inclusion of propositions.

We can observe a parallel dispute in the temporal case. If eternalists are 
spatial theorists of time, they will say that $x$ exists at a time $t$ if and only if $x$ exists simpliciter. As Socrates has existed, he exists at some earlier time according to the familiar semantics for tense. It then follows that Socrates exists simpliciter given the above truth-condition. Of course, presentists cannot accept such an inference. If presentists are also linguistic ersatzists, they can avoid it by holding that $x$ exists at a time $t$ if and only if $t$ implies or includes the proposition that $x$ exists. Thus, temporal existence is just a matter of implication between propositions or set-theoretic inclusion of propositions. From this perspective, it appears that presentism is to eternalism what actualism is to modal realism.

In the rest of the paper, I will discuss the ersatzist framework that I have just outlined. Before providing details, I should make it clear what I will focus on. First, I will refrain from discussing reductionism about modality and tense. Lewis (1986: 150-7) criticizes his opponents by noting that linguistic ersatzists should still take a modal notion as primitive. Although this may count as a serious defect from the realist viewpoint, it is unclear whether actualists should really discard any modal notions. Likewise, giving a reductive account of tensed notions may not be 
presentists' primary purpose even if they can provide such an account. (For presentist reductionism, see Rasmussen 2012 and Tallant 2012.) Furthermore, it seems that there is a certain tradeoff relation between ontology and ideology: If one can avoid ontological commitment to certain things, there may be a good reason to take some notions as primitive.

Second, ersatzism about time (as opposed to ersatzist presentism) could be understood as a neutral theory independent of the dispute between presentists and eternalists. Ersatzists about time are no doubt friendly to presentists, but eternalists might also prefer a similar theory. For instance, Meyer (2013) has offered what he calls a 'modal theory of time' and, nonetheless, professes to be an eternalist. While presentists can naturally adopt ersatzism about time, eternalists who are also modal theorists need to explain why they deny a spatial theory of time and yet believe in the existence of past and future things, even though such a position is not obviously self-contradictory. To avoid unnecessary confusion, however, it is better to distinguish ersatzism about time from ersatzist presentism. Here onwards, I will mainly discuss the former. 


\section{Constructing possible worlds}

It may be tempting to think that a time is like a possible world because times are constructed out of similar linguistic entities as possible worlds. Furthermore, there is a sense in which existing at a time is not like existing at a place but like existing at a possible world. In ersatzism, the mere fact that Socrates exists at some past time does not imply that he exists simpliciter any more than the fact that a talking donkey exists at some possible world implies that it exists simpliciter. Thus, it may seem that a time and a world are of the same kind, and therefore that ersatzist actualists and ersatzist presentists are in the same boat.

However, it does not take long to realize that such identification fails. Meyer says:

Impressed by the success of the ersatz theorist, it is tempting to propose a similar strategy to the presentist. The idea would be to interpret times as "ways the present might have been"; as abstract representations of "possible presents". 
But this project quickly runs into trouble. While every way the world might have been qualifies as a possible world, not every way the present might have been is a time. At best, times are ways the present was, is, or will be, and not every way the present might have been is of this kind: some possible presents never happen. (2005: 220)

Thus, Meyer concludes that the world-time parallel collapses.

Crisp, an advocate of ersatzist presentism, admits Meyer's point. He discusses a similar problem from a different perspective and says:

I think the presentist should hold that there is one and only one ersatz B-series, all right, but that it does not include all the abstract times among its members. It counts among its members only some of the abstract times-those that did, do or will represent the world... To be sure, many of these abstract times are such that they could have born the earlier than relation to other times, but as a matter of contingent fact, they don't. What abstract times get "hooked up" by 
the earlier than relation, on this picture, is a contingent matter that varies from possible world to possible world. (2007: 104)

Crisp also thinks that there is only one ersatz B-series and that it is a contingent matter which times constitute the B-series.

However, Crisp highlights that the problem is faced by not only presentists but also eternalists. He says:

Note that similar questions arise for the eternalist who believes in concrete times. Why do the concrete times come temporally ordered in the way they do? What explains the fact that they have this order and not another? Eternalists have answered such questions in various ways, but as plausible an answer as any is that they just do come ordered this way, and there's an end 'ont. It's a brute, contingent fact, on this view, that concrete times come temporally ordered as they do. (Ibid.) 
In this passage, Crisp suggests that ersatzist presentists should not surrender hope because the very same question arises in any view on time: Why is the actual B-series—ersatz or not—such and such rather than otherwise? Both presentists and eternalists cannot answer this question. They simply assume that there is a brute fact about the B-series that is determined as a matter of contingency.

What Crisp says above is suggestive in some respects but his comment is, at best, a partial defence against Meyer's objection. Crisp seems to agree with Meyer that while all abstract representations of ways the world might have been may count as possible worlds, not all abstract representations of ways the present might have been count as times. If so, the parallel between time and modality collapses, and any argument for presentism that rests upon it will accordingly be in danger. Historically speaking, ersatzist presentism has been motivated by the plausibility of its actualist counterpart: Those who think that linguistic ersatzism is the best position to take should also admit that ersatzist presentism is promising for the same reason. Meyer would argue that such a line of thought is too crude.

In what follows, I offer a plausible account of the relationship between 
time and modality. While admitting that a time is not like a possible world, I suggest that a possible world should be identified with an ersatz B-series-a series of possible presents ordered by the relevant temporal relation. More precisely: (i) any ersatz time may count as a possible present; (ii) each possible world is constructed out of some of these possible presents in temporal order with a certain structure and (iii) both times and worlds may still be regarded as abstract representations of ways things might have been. I explain this picture in more detail below.

First, I hold that any maximally consistent proposition defined as an ersatz time may count as a way the world might have been at a time even if it does not represent the actual way things were, are, or will be. For instance, it seems possible that, at a certain time, it is raining, someone called 'Socrates' exists, there are no birds in the sky and even pigs fly. Whatever we think is a coherent description of the world could have happened at a time even if it may strike us as improbable given what is actually happening. Unless one poses arbitrary restrictions, the ways the world might have been at a time should accord with the 
ways the present might have been, including exotic possibilities such as a flying pig

(if it is consistent). I then suggest that instead of starting from possible worlds, one

may start from possible presents.

Second, while a possible present represents how the world might have been at a time, a possible world should comprise some of these possible presents in temporal order with a topological structure (liner, branching, circular, dense, discrete, no-beginning, no-ending, or whatever structure it might be). Consequently, the same set of possible presents can make different possible worlds. Randomly collecting some possible presents and putting them in a certain order with a certain structure, we will have a great variety of possible ersatz B-series. One may expect that a resulting ersatz B-series will be able to perform the same job as a possible world.

Third, although an ersatz B-series that represents a persisting world is a structured representation rather than a simple representation of how it might have been at a time, it is still an abstract entity. In this respect, a time and a world are similar, and no new kind of entity is thereby created. Certainly, assimilation of a 
possible world into a possible ersatz B-series would complicate an analysis of modality and tense because it would imply that they no longer are two separate notions. Thus I analyse as follows:

\section{The Analysis of Modality (AM)}

It is possible that $P$ if and only if for some possible world $w$ accessible from the actual world $W @, W$ contains some time $t$ such that $t$ implies that $P$ is true.

\section{The Analysis of Tense (AT)}

It was the case that $P$ if and only if the actual world W@ contains some time $t$ such that $t$ is earlier than the present time $t_{\circledast}$ and implies that $P$ is true.

(I omit the future case; however, a similar truth-condition can be given on the assumption that the structure of time is linear.) This complication is what we should expect if we wish to have a complete analysis of modality and tense.

With this conception of times and worlds, we can now observe that the 
number of possible presents does not depend on any contingent fact. A possible present determines what could have happened at a time, and vice versa. Once we have all possible presents, we also have all possible ersatz B-series through recombination of ersatz times in a certain order with a certain structure. Therefore, the number of possible worlds does not depend on any contingent fact either. It is, nonetheless, contingent which ersatz B-series represents the actual world and which possible present represents the present moment correctly. The result is just what we expect.

It should be clear how ersatzists about time could respond to Meyer, who says that one cannot treat times analogously to worlds because not all abstract representations of ways the present might have been are times. In reply, I say that each possible present is an ersatz time because it represents how the world might have been at a time, and that each possible world is an ersatz B-series because it represents how the world might been through time. We need not determine which possible presents represent how things were, are or will be before we construct an ersatz B-series. After one ersatz B-series is contingently selected as representing 
the actual world, the ersatz times that constitute it can be regarded as the actual times. ${ }^{1}$

\section{Further questions}

In this section, I consider the following three questions: First, whether the method

of constructing an ersatz B-series can accommodate all the possible worlds we need;

second, how one can reasonably maintain the belief that there is just one world while making use of possible-world semantics and third, in what respect it is advantageous to take the approach that I offer.

\subsection{Times enough for worlds}

Can possible ersatz B-series cover all the possible worlds that we need? It depends on what we think of 'possible worlds'. If we use the term in the Lewisian sense,

\footnotetext{
${ }^{1}$ An anonymous referee of this journal calls my attention to the recent work by Rasmussen (2015: fn. 9). It should be noted that although his framework is similar to mine, there is a remarkable gap between our positions. Whereas Rasmussen has proposed a presentist approach to ersatz possible worlds by way of defending his Tenseless Presentism, I am inclined to accept tense primitivism (at least primitive actuality and presentness) in my theory and more serious about giving a uniform account of time and modality rather than arguing by analogy. I will clarify some merits of the theory in detail through Section 4 .
} 
ersatzists can hardly meet what modal realists would demand. Lewis (1986: 157-65) complains that there should be some possible worlds that linguistic ersatzists would fail to provide or adequately distinguish. They include a world where there is two-way eternal recurrence, a world that comprises a perfect crystalline lattice and a world where there are alien properties. Even if Lewis is right regarding this point, it is still arguable whether ersatzists should meet his demand in the first place. Significantly, the problem (if it matters at all) should face any version of linguistic ersatzism. If we think of 'possible worlds' just as ersatzists do, no further problem should arise.

Moreover, ersatzists about time may contend that they can offer a fine-grained analysis of modality. It could have happened at a certain time that I was killed in some accident. It is of course possible that I was born. While there is an ersatz B-series in which I first come into being and then cease to be, it is quite uncertain whether a reversed version of this story is possible. I believe that such a strange story cannot happen in a world whose temporal structure is similar to that of ours. Even in a time travel story, not all sequences of events are possible. For 
instance, killing my grandfather before my birth is utterly impossible, which Lewis

(1976) also admits though he holds that some time travel stories are coherent. This

suggests that the notion of a possible world is doubly modal. It not only concerns

what is possible at a time, but also concerns what sequence of events is possible.

Accordingly, the principle of temporal recombination may be restricted in some

cases. Hence, there are not as many possible worlds as one might think.

\subsection{One-world heir line}

Actualists usually claim that the actual world is a concrete object while possible worlds are mere abstract objects. This is prey to the following objection raised by

Lewis:

I have already said that it would gain us nothing to identify possible worlds

with sets of sentences (or the like)... Not only would it gain nothing: given that

the actual world does not differ in kind from the rest, it would lead to the

conclusion that our actual world is a set of sentences. Since I cannot believe 
that I and all my surroundings are a set of sentences (though I have no argument that they are not), I cannot believe that other worlds are sets of sentences either. (1973: 86)

At first glance, this seems to be a merely verbal dispute. Actualists do not have to admit that the actual world and other worlds does not differ in kind, and they may use the word 'world' differently in different contexts. However, a potential problem lurks nearby. If actualists cannot but use the same word for two distinct kinds of objects, one would be at a loss as to why such different usages are both legitimate. Modal realists, on the other hand, consistently use the word to refer to a concrete world.

I suggest that actualists should also use the word 'world' exclusively for the concrete world and have another word for a possible world; and they can if they are ready to assimilate a possible world into an ersatz B-series. Actualists may then add that there is only one world because no world is an abstract object. One might think that although my suggestion avoids the ambiguity concerning the different 
usages of the same word 'world', it would still involve a double meaning concerning an ersatz B-series. Certainly, it is true to say that there is a distinction between the actual ersatz B-series and a merely possible ersatz B-series; however, all ersatz B-series, including the actual one, are equally abstract. In ersatzism about time, no time is treated as anything like a place: All times-present or not-are abstract. As a result, all B-series-actual or not-are abstract. It is an ersatz B-series that should play the role of an abstract possible world. ${ }^{2}$

\subsection{The world-time parallel}

Those who believe in the parallel between time and modality might, nonetheless,

2 There may be another merit in taking a possible world as an ersatz B-series. If an ersatz possible world is to describe the world fully, it may be argued that it should also include all abstract representations of what might have been (i.e. other possible worlds). As Lewis says, "[i]t is as if we had a library, and every book in the library describes fully ... every book in the library", but "[b]ooks being the finite things they are, of course that is impossible" [1986: 151]. In response, ersatzists might say that each possible world only represents how concrete things (including the world as an concrete object) might have been but nothing else, so that the alleged problem will not occur in their theory. Under the approach that I propose here, we can deal with the issue more naturally. It is the nature of an abstract time that it only represents how concrete things (including the concrete world) are at that time but nothing else. Thus, an ersatz B-series constructed out of those times does not include other times or B-series. In short, an ersatz B-series (i.e. a possible world) is a complete series if and only if it represents how concrete things were, are and will be but nothing else. I thank the reviewer for raising this issue. 
think that a time and a world are two distinct notions (cf. Cresswell and Rini 2012); however, I have argued that there should be something more than an analogy. Times are abstract representations of ways the present might have been, and a possible world is an ersatz B-series constructed out of those ersatz times in temporal order with a certain structure. Thus, the ersatzist theory that I offer implies not only that time and modality are analogous in some ways but also that times constitute a possible world in the literal sense. In other words, time is a basic (if not fundamental) entity and a possible world is a derivative entity.

It is also important to distinguish what I have suggested here from the claim that a time is a possible world (cf. Bigelow 1991 and Parsons 2003). A time is like a possible world in the sense that both are abstract; however, I do not think that the notion of a time can be assimilated to that of a world. First, as I have said, the word 'world' should be used exclusively to refer to the concrete global object that can undergo various changes in properties or relations just as concrete local objects do. Second, a time cannot be a possible world unless the world is represented as an 
instantaneous object: Rather, times constitute a possible world. ${ }^{3}$ Finally, this view is more parsimonious in both ontology and ideology because it posits no extra ingredients to identify a possible world with a B-series, and it helps in stopping usage of the problematic notion of a possible world.

\section{Conclusion}

To summarise, I have argued that ersatzists about time have a better way of explaining what possible worlds are. An ersatz time is an abstract representation of how the world might have been at a time, and an ersatz B-series is an abstract representation of how the world might be through time. This view is a kind of

\footnotetext{
${ }^{3}$ It may seem that my proposal implies that there is no possible world without time, but this implication will seem costly to those who think that there could be a world without change or time. I respond to this objection in the following way. First, an ersatz B-series constructed out of just one time may count as a possible world even though it sounds strange to call it a series. An instantaneous world is the limit case where the series has a single member, and my proposal should allow such a case if it is in fact logically possible. (I do not think that a possible present must stand in a temporal relation to some other time by its nature.) Second, there is a way for ersatzists about time to deal with the possibility of time without change that have been discussed since Shoemaker (1969) although it is still highly controversial whether one should really accept such a possibility. See Bourn (2006: 66-8). Alternatively, if only multiplicity matters, one could simply distinguish one and the same set of propositions by pairing it with infinitely many integers.
} 
constructivism about possible worlds. As in many other disputes between constructivists and realists, there should be issues to which realists draw attention but constructivists do not. In the case of modality, however, I believe I am not the only one who stands on the constructivist side. Following these constructivists, ersatzists about time can give a plausible account of modality without loss.

\section{References}

Bigelow, J. 1991. Worlds Enough for Time. Noûs 25: 1-19.

Bourne, C. 2006 A Future for Presentism. Oxford: Clarendon Press.

Cresswell, M. J. and A. A. Rini. 2012. The World-Time Parallel. Cambridge University Press.

Crisp, T. M. 2007. Presentism and the Grounding Objection. Noûs 41: 90-109.

Leiws, D. 1973. Counterfactuals. Blackwell Publishers.

Lewis, D. 1976. The Paradoxes of Time Travel. American Philosophical Quarterly 13: 
$145-52$.

Lewis, D. 1986. On the Plurality of Worlds. Oxford: Blackwell.

Meyer, U. 2005. The Presentist's Dilemma. Philosophical Studies 122: 213-25.

Meyer, U. 2013. The Nature of Time. Oxford: Clarendon Press.

Parsons, J. 2003. A-theory for Tense Logicians. Analysis 63: 4-6.

Rasmussen, J. 2012. Presentists May Say Goodbye to A-Properties. Analysis 72: 270-76.

Rasmussen, J. 2015. Tenseless Times. Philosophical Studies (Published Online): http://link.springer.com/article/10.1007\%2Fs11098-015-0466-5?

Shoemaker, S. 1969. Time without Change. Journal of Philosophy 66: 363-81.

Talllant, J. 2012. (Existence) Presentism and the A-theory. Analysis 72: 673-681.

\begin{abstract}
It is sometimes argued that there is an analogy between time and modality: What is true of time, mutatis mutandis, should be true of modality, and vice versa. However,
\end{abstract}


I think that the importance of this analogy has not been truly appreciated in the literature. In this paper, I try to offer a plausible account of the relationship between time and modality based on what is known as presentist ersatzism. If the attempt succeeds, it will be shown that ersatzists about time are better able to explain what possible worlds are.

Keywords: Presentism; Ersatzism; Times; Possible Worlds 